\title{
A Superconducting Magnetic Energy Storage-Emulator/Battery Supported Dynamic Voltage Restorer
}

\author{
A. M. Gee, F. Robinson, Member, IEEE and W. Yuan.
}

\begin{abstract}
This study examines the use of superconducting magnetic and battery hybrid energy storage to compensate grid voltage fluctuations. The superconducting magnetic energy storage system (SMES) has been emulated by a high current inductor to investigate a system employing both SMES and battery energy storage experimentally. The design of the laboratory prototype is described in detail, which consists of a series-connected three phase voltage source inverter used to regulate $\mathrm{AC}$ voltage, and two bidirectional DC/DC converters used to control energy storage system charge and discharge. 'DC bus level signaling' and 'voltage droop control' have been used to automatically control power from the magnetic energy storage system during short-duration, high power voltage sags, while the battery is used to provide power during longer-term, low power under-voltages.

Energy storage system hybridisation is shown to be advantageous by reducing battery peak power demand compared with a battery-only system, and by improving long term voltage support capability compared with a SMES-only system. Consequently, the SMES/battery hybrid DVR can support both short term high-power voltage sags and long term undervoltages with significantly reduced superconducting material cost compared with a SMES-based system.
\end{abstract}

Index Terms-- Dynamic Voltage Restorer (DVR), Energy Storage Integration, Sag, Superconducting Magnetic Energy Storage, Battery.

\section{INTRODUCTION}

$\mathrm{T}$ HE improvement of power quality is an important objective for electrical utilities and industrial and commercial consumers. Highly intermittent distributed generation, rapidly changing loads, and direct-off-line power electronic systems all contribute to reduced power quality causing equipment downtime, overload and failure leading to lost revenue [1].

Voltage disturbance is a common problem and undervoltage conditions have been seen to occur more frequently than overvoltage conditions [2]. Short-term under-voltage sags

Manuscript received 02/11/2015. This work was supported in by EPSRC grant EP/K01496X/1.

Dr. F. Robinson (e-mail: F.V.P.Robinson@bath.ac.uk) and Dr. W. Yuan (e-mail: W.Yuan@bath.ac.uk) are with the Electronic and Electrical Engineering Department, University of Bath, Bath BA2 7AY, U.K.

A. Gee (e-mail: ag15969@bristol.ac.uk) was with the Electronic and Electrical Engineering Department, University of Bath, Bath BA2 7AY, U.K and is now with Department of Electrical and Electronic Engineering, University of Bristol, Bristol, BS8 1UB, U.K. are defined in IEEE Std. 1159-1995 [3] as a decrease to between 0.1 and 0.9 p.u. (per unit) r.m.s voltage for durations of 0.5 cycles to $1 \mathrm{~min}$. They occur more frequently than longterm under-voltages with significant costs to industry [4]. Long-term under-voltage events are defined as a measured voltage less than 0.8-0.9 p.u. r.m.s voltage, lasting longer than one minute [3] and can lead to load shedding and potentially to voltage collapse [5]. The study below presents a means by which both short-term and long-term voltage fluctuations can be mitigated at the load using short-term magnetic energy storage and long-term battery energy storage.

\section{LITERATURE REVIEW}

Methods to mitigate long-term voltage disturbance, such as load disconnection [6] or modification of loads for greater low-voltage ride-through capability may be impractical [7]. Alternatively, supply voltage can be stabilised by tap changing transformers, uninterruptable power supplies (UPS), shuntconnected compensators, or dynamic voltage restorer (DVR) systems. Tap changing transformers have been shown to suffer from a slow response time and can only output discrete voltage levels [8]. UPS systems provide the complete voltage waveform during a power failure and may prove costly and unnecessary in the event of partial voltage sags. A DVR is a series-connected device capable of voltage compensation with fast response time by injecting a voltage in series with the supply.

DVR systems can be self-supporting by using power from the grid to mitigate disturbances [9]. Alternatively, DVR systems can use energy storage to provide power during compensation such as capacitors [10] for short-term storage or batteries [11] for longer-term storage. Nielsen and Blaabjerg [12] have shown that capacitor-supported DVR systems can suffer from relatively poor performance for severe and long duration sags. A recent study has shown that an ultra-capacitor based DVR [13] can be used to mitigate short-term voltage sags lasting less than one minute. Wang and Venkataramanan [14] have shown that flywheels are a viable short-term energy storage technology for use with voltage restorer systems both experimentally and by simulation. Kim et al. [15] have described a $3 \mathrm{MJ} / 750 \mathrm{kVA}$ SMES-based DVR system and shown experimental results confirming that SMES is suitable for the compensation of short-term voltage sags. Shi et al. [16] have used a system-level simulation to also show that SMES 


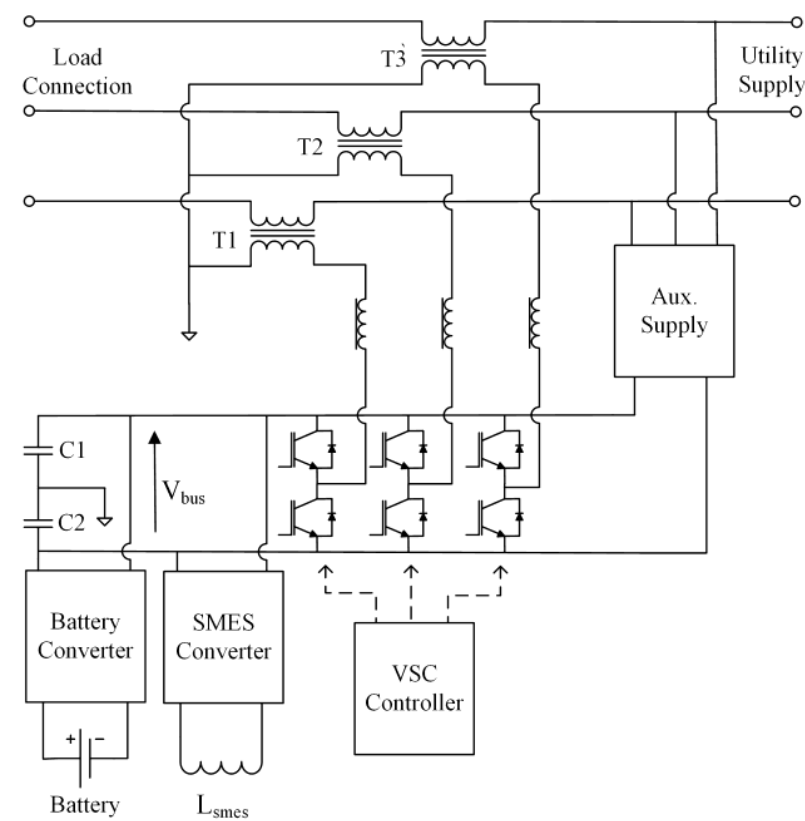

Figure 1. Hybrid energy storage DVR system configuration.

energy storage is capable of compensating voltage sags lasting $100 \mathrm{~ms}$.

Short-term voltage compensation alone may not be sufficient to protect a sensitive load as both long-term [5], [17] and short-term [2-4] voltage stability has been shown to present a problem for many consumers. For this reason, this study considers the use of SMES/battery hybrid energy storage to compensate long and short-term voltage fluctuations. Woong et al. [18] have also considered a SMES/battery hybrid and shown it is viable for smoothing of renewable energy generator output power and can result in reduced energy storage system capacity and prolonged battery life. Li et al. [19] have shown that a SMES/battery energy storage system can improve battery lifetime in electric buses. Deng et.al. [20] have presented a SMES/battery hybrid system for reducing peak grid power in an electric vehicle charging station. Nie et al. have also presented a SMES/battery hybrid system and shown its feasibility in dealing with long term and short term charge/discharge events in a wave energy conversion system [21]. This study extends previous simulation-based SMES/battery hybrid system studies [18-21] by considering the hardware implementation of a SMES/battery energy storage system. The design is shown to be capable of interfacing SMES and battery energy storage systems and controlling their power sharing to support a three phase load, during both long-term and short-term voltage sags. This has benefits in terms of improved long-term voltage support capability and reduced costs compared with a purely SMES-based system. Additional benefits include reduced battery power rating requirement and an improvement in expected battery life compared with a battery-only system.

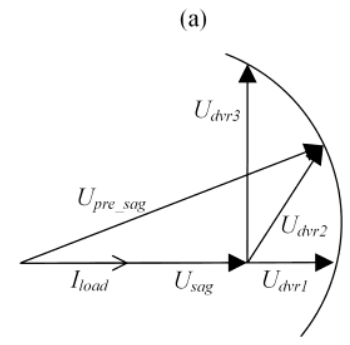

(b)

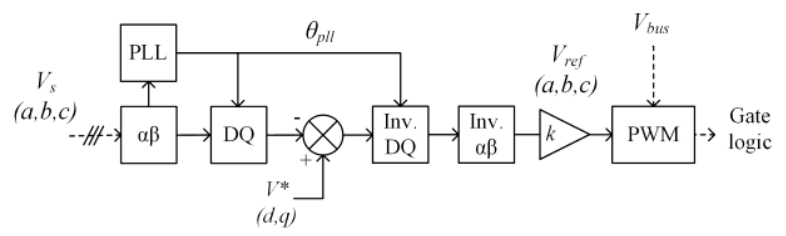

Figure 2. Vector diagram of DVR control strategies [1] $U_{d v r I}$ : 'In phase compensation'. $U_{d v r 2}$ 'Pre-sag compensation'. $U_{d v r 3}$ : 'Energy optimal control'. (b) DVR control system.

\section{Methodology}

Fig. 1 shows the DVR system considered. The SMES has been emulated by a $15 \mathrm{mH}, 100 \mathrm{~A}$ inductor. During a voltage error a three-phase inverter is used to generate the compensation voltage at the primary of the injection transformers (T1-T3) so that the load voltage remains close to nominal. DC/DC converters are used to interface the battery and SMES-emulator to the DC bus. An auxiliary supply (Aux. Supply) is used to support the DC bus during standby operation and charge the energy storage devices. The auxiliary supply is disconnected and the energy storage devices provide the necessary power for the inverter to support the load during a voltage error.

\section{A. DVR Control}

The objective of the DVR control system is to minimise supply voltage variations at the load terminals. This is achieved by generating a compensating voltage at the series injection transformer terminals. The phasor diagram in Fig. 2(a) shows various DVR voltage control techniques. 'In phase compensation' causes the compensating voltage to be in phase with the incoming supply voltage and has been shown to result in the lowest DVR power rating [22]. 'Pre-sag compensation' preserves the phase of the incoming supply at the time a sag occurs which can be beneficial in protecting loads that are sensitive to phase disturbances. 'Energy optimal' control is used to minimise DVR energy storage requirement by injecting a voltage in quadrature to the load current. 'In phase compensation' and 'Pre-sag compensation' have been considered in this study. The control scheme was implemented in the synchronous reference frame as shown in Fig. 2(b) by converting three phase $\mathrm{AC}$ quantities to equivalent two phase quantities:

$$
\left[\begin{array}{l}
V_{s \alpha} \\
V_{s \beta}
\end{array}\right]=\frac{2}{3}\left[\begin{array}{ccc}
1 & -1 / 2 & -1 / 2 \\
0 & \sqrt{3} / 2 & -\sqrt{3} / 2
\end{array}\right]\left[\begin{array}{c}
V_{s a} \\
V_{s b} \\
V_{s c}
\end{array}\right]
$$




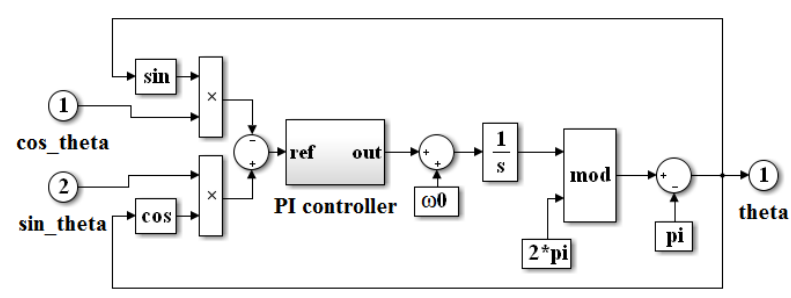

Figure 3. Simulink implementation of PLL algorithm where $\omega 0$ is the fundamental output frequency in rad/s.

$$
\left[\begin{array}{c}
V_{s d} \\
V_{s q}
\end{array}\right]=\left[\begin{array}{cc}
\cos \theta_{p l l} & \sin \theta_{p l l} \\
-\sin \theta_{p l l} & \cos \theta_{p l l}
\end{array}\right]\left[\begin{array}{c}
V_{s \alpha} \\
V_{s \beta}
\end{array}\right]
$$

where $V_{s a, b, c}, V_{s a, b}, V_{s d, q}$ are the supply voltages and $\theta_{p l l}$ is the estimated supply phase angle.

A phase-locked loop (PLL) was used to determine the phase angle $\theta_{p l l}$ of the incoming supply based on an algorithm which is robust in the presence of harmonics, non-symmetry and transients [23]. Fig. 3 shows a Simulink implementation of the PLL algorithm. This algorithm minimises the sine of the phase error term causing the control system to be non-linear. For this reason, the PI controller gains were tuned empirically. The PLL algorithm requires the cosine and sine of the incoming supply angle as inputs which can be obtained geometrically using the orthogonal reference frame voltages from (1) as:

$$
\begin{aligned}
& \cos (\theta)=\frac{V_{s \alpha}}{\sqrt{V_{s \alpha}{ }^{2}+V_{s \beta}^{2}}} \\
& \sin (\theta)=\frac{V_{s \beta}}{\sqrt{V_{s \alpha}{ }^{2}+V_{s \beta}^{2}}}
\end{aligned}
$$

The PLL controller can be tuned to preserve the phase of the incoming supply before a sag event with phase jump or, alternatively, the PLL can be made to track the phase of the incoming supply during a sag with phase-jump. Consequently, by changing the PLL gains the system can be controlled to provide 'in phase' or 'pre-sag' compensation. Fig. 4 illustrates the results of tuning the PI controller in this way.

To detect the presence of a voltage error, the following inequality was used [24], [25]:

$$
\sqrt{\left(V^{*}{ }_{d}-V_{s, d}\right)^{2}+\left(V^{*}{ }_{q}-V_{s, q}\right)^{2}} \geq V_{\text {threshola }}
$$

where $V_{s, d, q}$ is the measured load voltage and $V_{d, q}^{*}$ is the desired nominal voltage in the synchronous reference frame. Inequality (5) was also used to trigger the disconnection of the DC bus auxilliary power supply (see Fig. 1).

The compensation voltage $V_{\text {refd, } q}$ is determined, based on the error between the desired nominal voltage and the supply voltage:

$$
V_{r e f d, q}=V_{d, q}^{*}-V_{d, q}
$$

The PWM phase reference voltages $V_{r e f a, b, c}$ were generated by transforming the required compensation voltage to the rotating
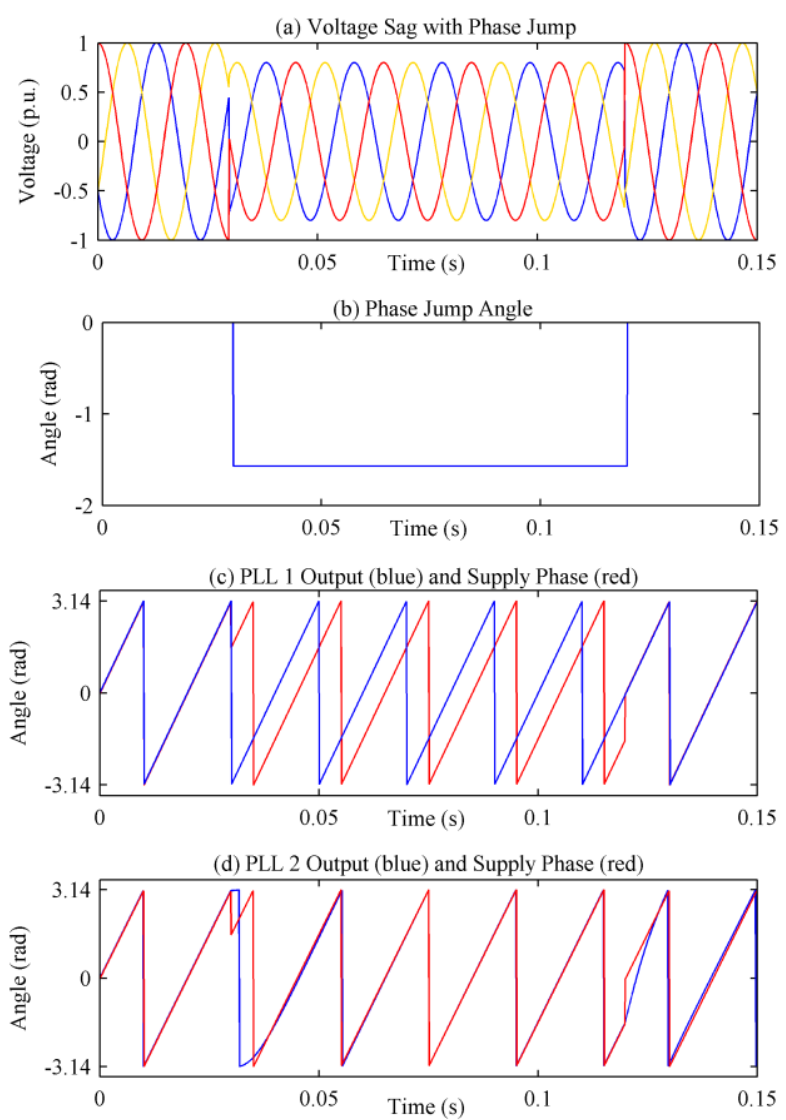

Figure 4. Simulated PLL Algorithm results: (a) Simulated voltage sag with phase jump (b) Phase jump angle (c) Blue trace: supply phase angle. Red trace: PLL output: 'Pre-sag compensation' with controller gains: $k_{p}=0.5, k_{i}=5$, (d) Blue trace: supply phase angle. Red trace: PLL output: 'In phase compensation' with controller gains $k_{p}=200, k_{i}=50$.

three phase reference frame:

$$
\begin{aligned}
& {\left[\begin{array}{l}
V_{\text {ref } \alpha} \\
V_{\text {ref } \beta}
\end{array}\right]=\left[\begin{array}{cc}
\cos \theta_{p l l} & -\sin \theta_{p l l} \\
\sin \theta_{p l l} & \cos \theta_{p l l}
\end{array}\right]\left[\begin{array}{c}
V_{\text {refd }} \\
V_{\text {refq }}
\end{array}\right]} \\
& {\left[\begin{array}{l}
V_{\text {refa }} \\
V_{\text {refb }} \\
V_{\text {refc }}
\end{array}\right]=k \frac{3}{2}\left[\begin{array}{cc}
2 / 3 & 0 \\
-1 / 3 & 1 / \sqrt{3} \\
-1 / 3 & -1 / \sqrt{3}
\end{array}\right]\left[\begin{array}{l}
V_{\text {refa }} \\
V_{r e f \beta}
\end{array}\right]}
\end{aligned}
$$

The injection voltages, $V_{r e f a, b, c}$, were multiplied by a feedforward constant, $k$ to compensate for losses within the power stage.

Sine-wave pulse width modulation (SPWM) or space vector modulation (SVM) were considered for generating the inverter output voltage. SVM is advantageous due to better utilisation of the DC bus voltage and which allows deeper sag compensation. However, SPWM allows the possibility to mitigiate unbalanced faults so this technique was implemented in this study. The inverter control was implemented using a Texas Instruments F28069 32-bit micro-controller by discretisation of the control and PLL algorithms. The inverter system parameters are listed in the Appendix, Table AI. 


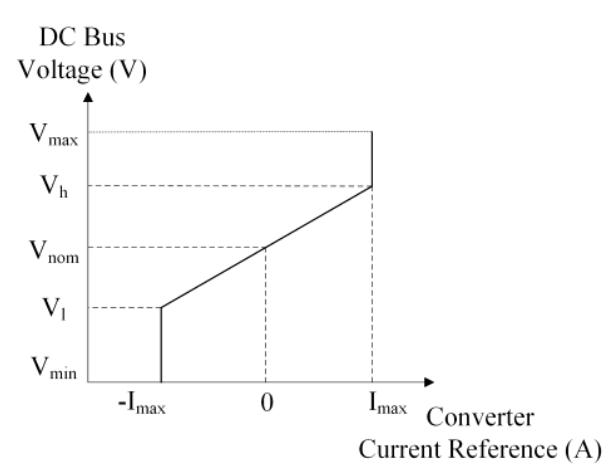

Figure 5. Energy storage systems active current droop control.

\section{B. Energy Storage top-Level Control}

The objective of the top-level energy storage control strategy was to control the charge/discharge of each energy storage device. A current vs. voltage active droop characteristic was chosen as this strategy has been shown to provide good stability and active power sharing [26]. The converter reference currents are based solely on the level of the DC bus voltage which is advantageous as high-bandwidth communication between the three different converters is not necessary. The charge or discharge priority of an energy storage device can be adjusted raising or lowering its nominal DC bus voltage using a technique known as "DC bus signaling" [27]. The system was configured to prioritise the SMES-emulator to charge/discharge before the battery. By always prioritising the short term energy storage, battery power cycling is reduced which can improve battery lifetime [19].

The current droop characteristic for each device is shown in Fig. 5, and is made up of three regions of operation. When the DC voltage is above voltage level $V_{h(x)}$ (where $x$ refers to energy storage system 1 or 2 ) or below below $V_{l(x)}$, the converter current is limited to $I_{\max (x)}$ or $-I_{\max (x)}$. In between $V_{h(x)}$ and $V_{l(x)}$, current is controlled based on the linear current vs. voltage relationship:

$$
I_{x}=\left(V_{\text {nom }}-V_{\text {bus }}\right) k_{x}
$$

where $k_{x}$ is a droop coefficient $(\mathrm{A} / \mathrm{V})$ and $I_{x}$ is the energy storage converter reference current.

\section{SMES-Emulator System}

To reduce costs and be able to evaluate a SMES-battery hybrid DVR control platform, the SMES device was emulated by using a $15 \mathrm{mH}$ iron-core inductor in this study. The SMES converter was based on the asymmetric H-bridge configuration shown in Fig. 6. This converter was rated at up to 220A continuous current using forced air cooling. During charge, Q2 is held ON and Q1 is modulated whereas during discharge Q1 is held off and Q2 is modulated. The relationship between DC bus current, inductor current and duty ratio, is given by (12) and (13) for charge and discharge, respectively [16].

$$
I_{\text {csmes }}=I_{\text {smes }} D_{1}
$$

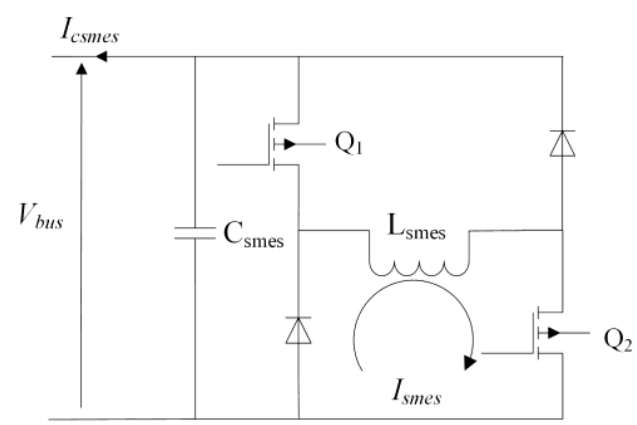

Figure 6. SMES DC/DC converter.

$$
-I_{\text {csmes }}=I_{\text {smes }}\left(1-D_{2}\right)
$$

For active current droop control according to (9), the desired converter output current Icsmes is given by (12).

$$
I_{\text {csmes }}=\left(V_{\text {bus }}-V_{\text {nom_smes }}\right) k_{\text {smes }}
$$

where $k_{\text {smes }}$ is the gradient of the droop controller and $V_{\text {nom_smes }}$ is the nominal voltage of the droop controller.

The required duty ratio can be determined by substituting Eq. (10) during charge or (11) during discharge into (12) and solving for duty ratio in real time. This allows the SMESinductor to be charged or discharged by simply raising or lowering the DC bus voltage relative to the nominal $V_{\text {nom_smes. }}$. The controller was implemented using a 16-bit microcontroller (PIC24HJ128GP502) with a switching frequency of $500 \mathrm{~Hz}$. This low switching frequency was chosen to allow for extreme (>>90\% and $<<10 \%$ ) duty ratio operation without causing overly narrow gate pulses. When operating at $100 \mathrm{~A}$ nominal current, conduction losses could be reduced significantly by the use of low on-state resistance MOSFETs as opposed to IGBTs in this system. This is expected not to be the case for larger systems, operating at significantly higher nominal currents and voltage ratings.

\section{Battery System}

A bidirectional synchronous-buck converter rated at $40 \mathrm{~A}$ output current with hysteresis current control was used to control battery current. This topology has been previously reported for use with interfacing an ultra-capacitor energy storage system to the DC bus in DVR application [13]. However, the proposed system differs from previous studies [13] in that a variable-frequency hysteresis current control has been used. This is advantageous as it features cycle-by-cycle current limiting, making it tolerant to short circuit faults. Also, the proposed technique is shown below to be globally stable over the operating range whereas typical current mode control techniques described previously [13] require slope compensation to ensure global stability [28]. Further advantages include good dynamic current-tracking capability, and robust performance despite variation and uncertainty in operating conditions [29].

Assuming lossless, ideal components, the inductor current in Fig. 7 is given by (13). 


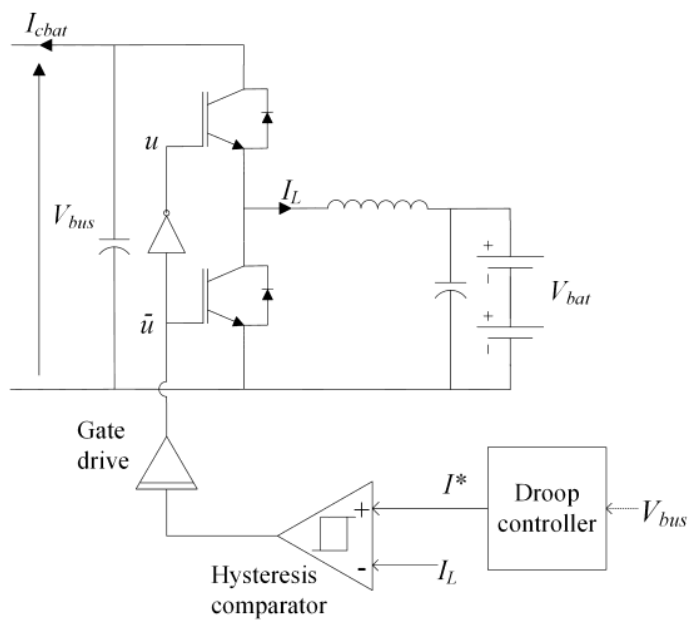

Figure 7. Battery DC/DC converter.

$$
L \frac{d I_{L}}{d t}=V_{b u s} u-V_{b a t} \bar{u}
$$

where $u$ is a gate drive signal and $V_{b a t}$ and $V_{b u s}$ are battery and DC bus voltages.

Sliding-mode control theory may be used to describe the current regulation strategy [30]. The objective in this case is to regulate the inductor $I_{L}$, such that it tracks the command reference current $I^{*}$. A function $\sigma=0$ can be defined as follows [30]:

$$
\sigma=I_{L}-I^{*}
$$

A switching control law which satisfies (15) such that $\sigma$ and its time derivative have opposite signs ensures the system will converge to the state $\sigma=0[30]$ and consequently $I_{L}=I^{*}$.

$$
\forall \sigma \neq 0: \quad \sigma \propto \&<0
$$

A switching control law which satisfies (15) is defined by (16), where $h$ is a small constant hysteresis band lying symmetrically about the set-point value.

$$
u=\left\{\begin{array}{l}
u=1, \quad \text { if } \sigma<-h \\
u=0, \quad \text { if } \sigma>h
\end{array}\right\}
$$

If $V_{b u s}$ is greater than $V_{b a t}$, then condition (15) is met, so this becomes an operational requirement.

For active current droop control according to (9), the following relationship can be written:

$$
I_{c b a t}=\left(V_{b u s}-V_{n o m_{-} b a t}\right) k_{b a t}
$$

where $I_{c b a t}$ is the battery $\mathrm{DC} / \mathrm{DC}$ converter reference current and $k_{b a t}$ is the gradient of the battery converter droop characteristic and $V_{\text {nom_bat }}$ is the nominal voltage of the battery converter droop controller.

The average current delivered to the DC bus can then be estimated, based on an ideal conversion ratio as follows:

$$
I_{c b a t t}=I * \frac{V_{b a t}}{V_{b u s}}
$$

To achieve active current droop control, the inductor current reference $I^{*}$ is set as follows:

$$
I^{*}=\left(V_{\text {bus }}-V_{\text {nom_bat }}\right) k_{\text {bat }} \frac{V_{\text {bus }}}{V_{\text {bat }}}
$$

\section{E. Energy Storage System Sizing}

DC bus signaling has been used to control the charge/discharge of the SMES-emulator system during shortterm voltage voltage-sags whereas the battery is used to mitigate longer-term voltage variations. Consequently, the sizing of the short-term and long-term energy storage systems can be treated separately. The inductive energy storage requirement is sized to mitigate short-term voltage sags whereas the battery system is sized to mitigate long-term under-voltages. The specific sag-depth and duration can be determined by measurement [31] or by simulation. Once the load power, depth of sag and sag duration are known, the SMES energy-storage requirement can be determined as has been previously reported [16]. The technique below extends this method [16] by including the inverter losses in the analysis.

While the DVR system is supporting the load voltage at its nominal value, the real power provided by the DVR to the load can be written:

$$
P_{\text {sag }}=\frac{3}{2}\left[\begin{array}{l}
\left(V_{d_{-} \text {nom }}-V_{d_{-} \text {sag }}\right) I_{d_{-} \text {load }} \\
+\left(V_{q_{-} \text {nom }}-V_{q_{-} \text {sag }}\right) I_{q_{-} \text {load }}
\end{array}\right]
$$

Assuming a sinusoidal current waveform, the losses in each IGBT and diode in the inverter, can be estimated based on previously reported loss models [32], [33]. Conduction loss in each IGBT is given by:

$$
\begin{aligned}
& P_{c i}= \\
& \left(\frac{1}{8}+\frac{M}{3 \pi} \operatorname{Cos} \varphi\right) R_{c e} I_{c m}^{2}+\left(\frac{1}{2 \pi}+\frac{M}{8} \operatorname{Cos} \varphi\right) V_{c e 0} I_{c m}
\end{aligned}
$$

where $M=$ modulation index, $R_{c e}=$ IGBT on-state resistance, $V_{c e 0}=$ IGBT forward voltage drop. $I_{c m}=$ IGBT forward current and $\varphi=$ power factor angle.

Conduction loss in each parallel diode is given by:

$$
\begin{aligned}
& P_{c d}= \\
& \left(\frac{1}{8}-\frac{M}{3 \pi} \operatorname{Cos} \varphi\right) R_{f} I_{c m}^{2}+\left(\frac{1}{2 \pi}-\frac{M}{8} \operatorname{Cos} \varphi\right) V_{f 0} I_{c m}
\end{aligned}
$$

where $R_{f}=$ diode on-state resistance, $V_{f 0}=$ IGBT forward voltage drop. $I_{c m}=$ diode current. The equivalent on-state resistance of the IGBT $\left(R_{c e}\right)$ and diode $\left(R_{f}\right)$ were determined by linear interpolation of datasheet values [34]. $M, \varphi$, and $I_{c m}$ can be found from the $d q$-axis components of the load current and required compensation voltage.

Switching loss in the IGBT and parallel diode can be determined as follows [32].

$$
P_{s w i}=\frac{1}{\pi}\left[E_{o n}\left(I_{c m}\right)+E_{o f f}\left(I_{c m}\right)\right] \frac{V_{d c}}{V_{d c_{-} r e f}}
$$




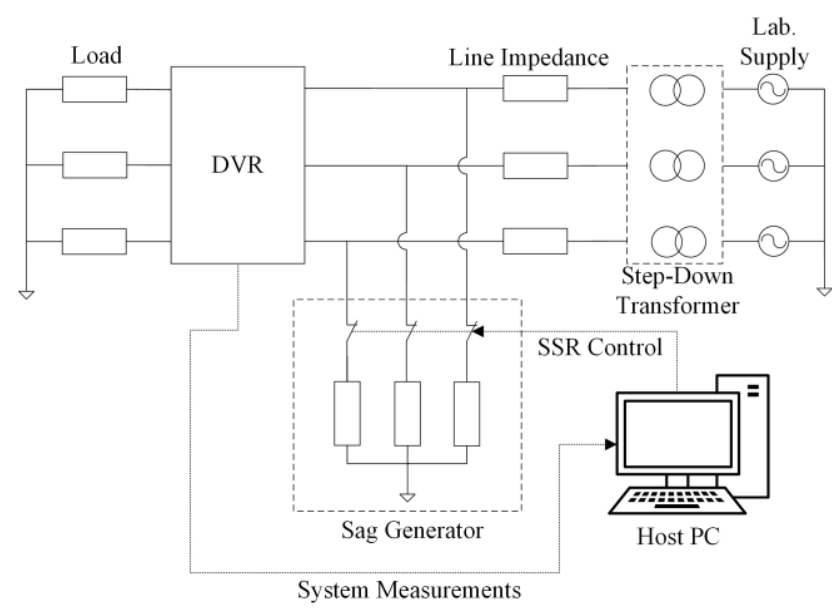

Figure 8. Experimental Set-up.

$$
P_{s w d}=\frac{1}{\pi} E_{r r}\left(I_{c m}\right) \frac{V_{d c}}{V_{d c_{-} r e f}}
$$

where $V_{d c}$ is the commutation voltage, $V_{d c_{-} \text {ref }}$ is the reference voltage at which the switching loss energies are given, $E_{\text {on }}\left(I_{c m}\right), E_{\text {off }}\left(I_{c m}\right)$ and $E_{R R}\left(I_{c m}\right)$ are IGBT turn-on, turn-off and diode reverse-recovery energies as a function of forward current [34]. The total inverter losses can then be estimated as:

$$
P_{i n v_{-} l o s s}=6\left(P_{c i}+P_{c d}+P_{s w i}+P_{s w d}\right)
$$

If a voltage disturbance has duration $T_{\text {sag }}$, then the capacity requirement of the energy storage systems connected to the DC bus can be found from (20) and (25) as follows.

$$
E_{\text {sag }}=\left(P_{\text {sag }}+P_{\text {inv_loss }}\right) T_{\text {sag }}
$$

For a given long-term under-voltage, the required discharge power provided by the DVR can be found from (20). The DVR energy can then be determined using the procedure shown in (21) - (26).

\section{F. Experimental Setup}

In order to verify the performance of the proposed DVR, a hardware prototype was constructed. The battery was a $48 \mathrm{~V}$, 75Ah sealed lead acid type and the SMES-emulator was $15 \mathrm{mH} / 100 \mathrm{~A}$ iron-core inductor. The nominal AC bus voltage was set to $120 \mathrm{Vac}$ using a step down transformer. The load was configured as a $1.4 \mathrm{~kW}$ star-connected resistor.

A simple laboratory sag generator was developed using solid-state relays to simulate faults to ground as shown in Fig. 8. System voltage measurements using isolating amplifiers were logged together with the battery and SMES-inductor currents using hall-effect current probes. The lead-acid battery was maintained at a full state of charge at the beginning of each experiment. To prevent battery overcharge, the maximum battery charge current was limited to a low value of $\sim 800 \mathrm{~mA}$ during stand-by operation. The DC bus voltage was

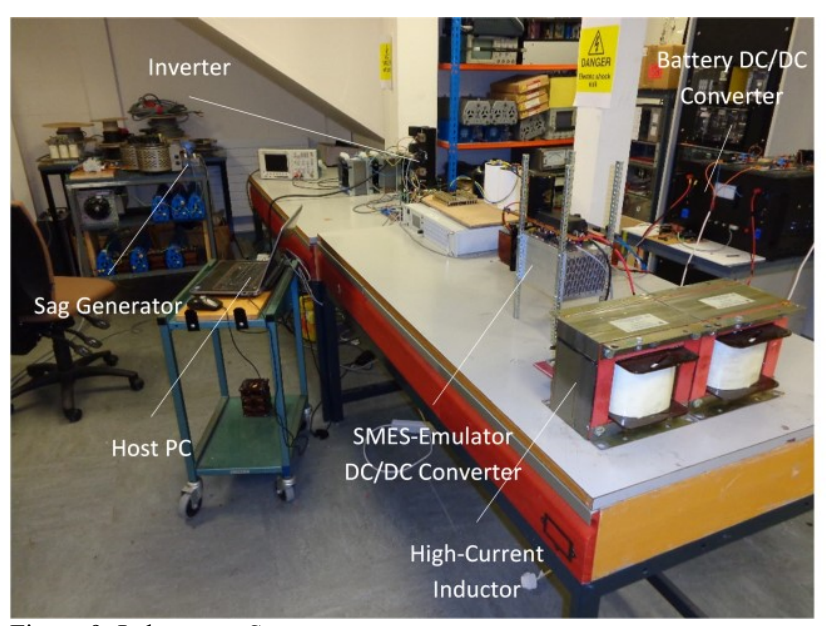

Figure 9. Laboratory Setup.

maintained at $160 \mathrm{Vdc}$ during standby operation using the auxiliary supply.

The short-term energy storage system capacity was estimated to support a sag to $35 \%$ of nominal voltage lasting approximately $100 \mathrm{~ms}$ using (26). The battery bank was sized based on available lead acid batteries. Energy storage device parameters are given in the Appendix, Tables AII and AIII. The experimental set-up is shown in Figs. 8 and 9.

\section{RESULTS}

Initially a three-phase voltage sag to $35 \%$ of nominal voltage, lasting $100 \mathrm{~ms}$ was used to demonstrate the response of the DVR and energy storage systems. From Fig. 10 it can be seen that the hybrid DVR system mitigates the voltage sag effectively during the sag event. The battery is discharged momentarily at $-1.45 \mathrm{~A}$ at the end of the sag when the inductor energy has been depleted.

The SMES-emulator was then removed from the system and the test was repeated. The system response to the same threephase sag with only battery energy storage is shown in Fig. 11. As the DC bus voltage falls below $140 \mathrm{Vdc}$ (the battery system nominal voltage) the battery is discharged to support the DC bus. The peak battery current is $21.13 \mathrm{~A}$ in this case and the DVR system can be seen to effectively mitigate the voltage sag. Fig. 12 shows an oscilloscope trace of the DVR injection voltage and supply voltage during a three phase sag.

To demonstrate the system performance during a long-term under-voltage, the experimental system was configured for a three-phase under-voltage dropping to $80 \%$ of nominal lasting 2s. The results are shown in Fig. 13. Initially, the SMES system can be seen to support the DC bus. As the voltage error lasts longer than the SMES-emulator can support the bus voltage, at time $=0.4 \mathrm{~s}$ the DC bus voltage falls to below $140 \mathrm{Vdc}$ and the battery energy storage system automatically discharges. 

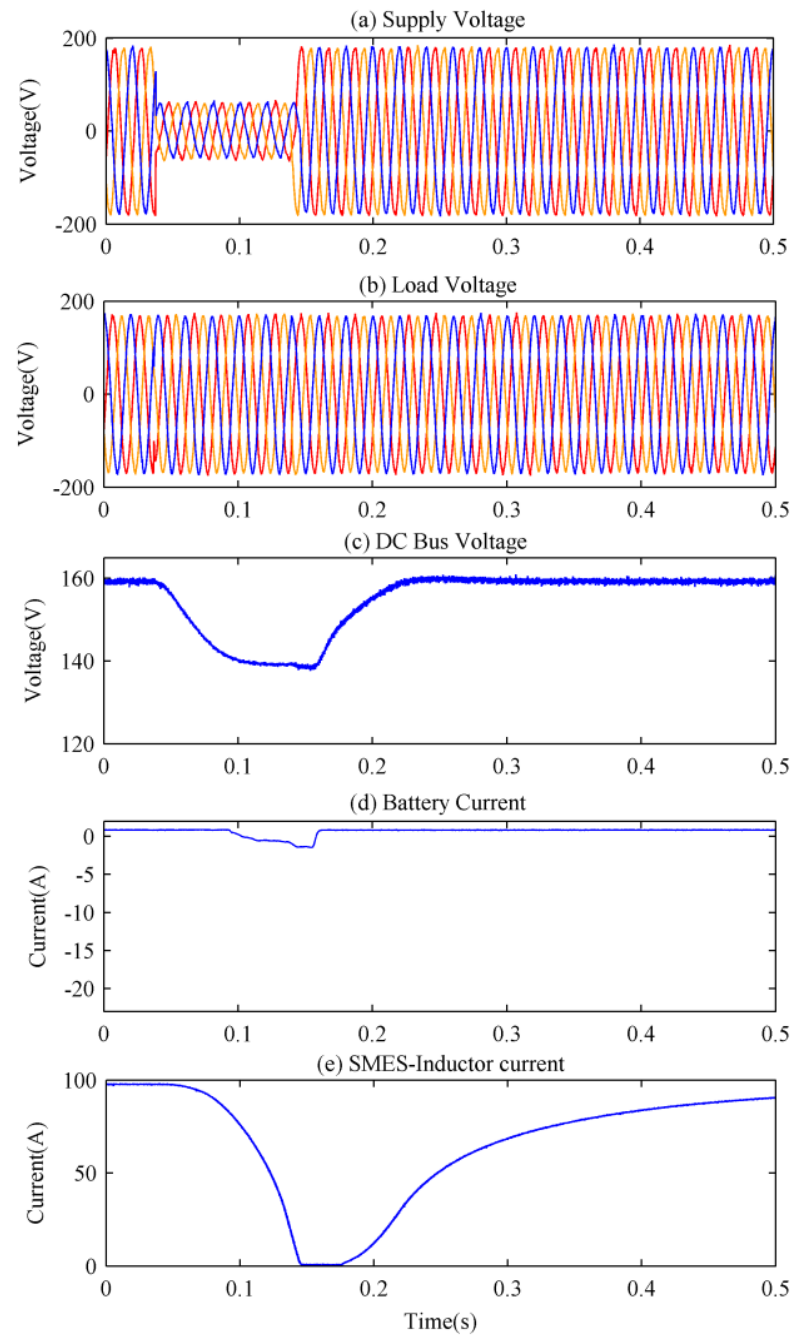

Figure 10. Hybrid System Experimental results: 0.1s Three phase sag to $35 \%$ of nominal voltage. (a) Supply voltages (b) Load voltages (c) DC Link Voltage (d) Battery Current (e) SMES-inductor current.

The battery then provides the necessary power to support the load for the remainder of the under-voltage condition. At Time $=2.1 \mathrm{~s}$ the under-voltage event has finished and the DC bus auxiliary supply reconnects. The battery and SMESemulator energy storage systems are then re-charged. While $2 \mathrm{~s}$ may not be considered a long-term under-voltage, this duration was chosen in order to be able to see the interaction between the energy storage systems clearly. The system response reaches a stable operating point after approximately $0.6 \mathrm{~s}$ which could be maintained to support the load until the battery bank is depleted.

\section{DISCUSSION}

By use of the SMES-emulator hybrid system, the peak battery current response during a three-phase sag to $35 \%$ of
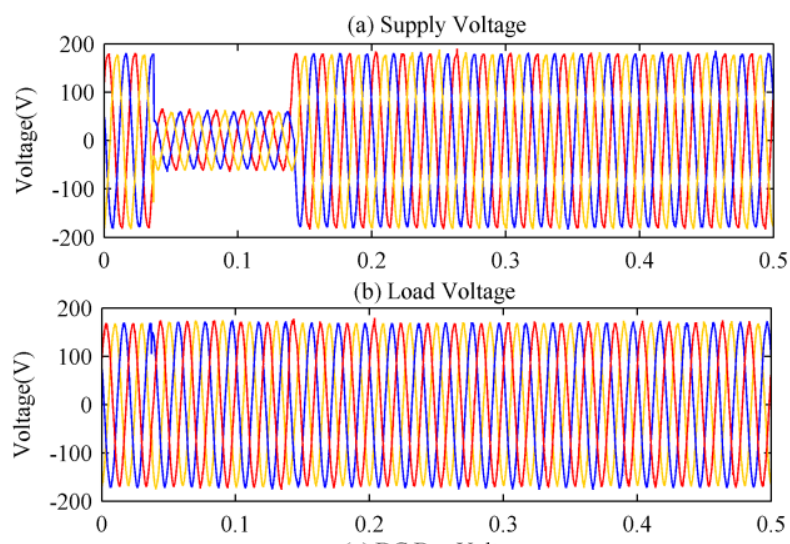

(c) DC Bus Voltage

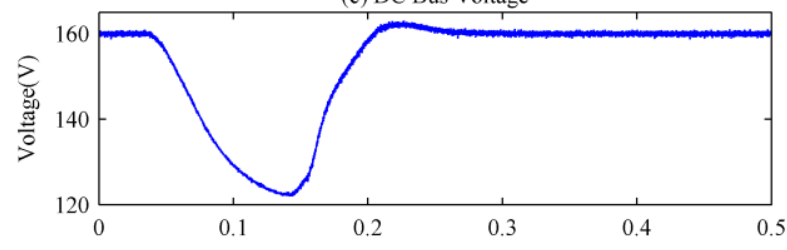

(d) Battery Current

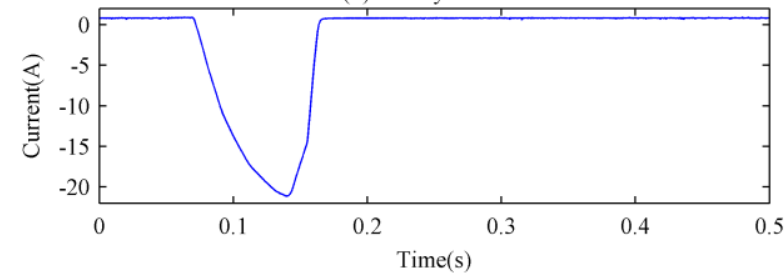

Figure 11. Battery System Experimental results: $0.1 \mathrm{~s}$ Three phase sag to $35 \%$ of nominal voltage. (a) Supply voltages (b) Load voltages (c) DC Link Voltage (d) Battery Current.

nominal was reduced to $1.45 \mathrm{~A}$ from $21.13 \mathrm{~A}$ compared with the battery-only system. This reduction in battery peak current can have significant benefits in terms of improved battery life, which is negatively affected by discharge current magnitude [35].

From Fig. 13, it can be seen that the long-term undervoltage performance of the system has been improved by the introduction of battery energy storage. One of the main shortcomings limiting the usage of SMES systems is the high cost of the superconducting material [36]. By integrating a battery, the hybrid DVR can be of significantly reduced cost compared with a SMES only DVR and still be capable of compensating a variety of short-term sags and long-term under-voltages. In order to estimate the potential scale of the cost reduction, the prototype system used in this study has been considered. The SMES-inductor was emulated to give $\mathrm{L}=$ $15 \mathrm{mH}$ at $100 \mathrm{~A}$ DC. The energy capacity of an equivalent SMES can be calculated:

$$
E_{H E S S_{-} S M E S}=\frac{L I^{2}}{2}=75(J)
$$




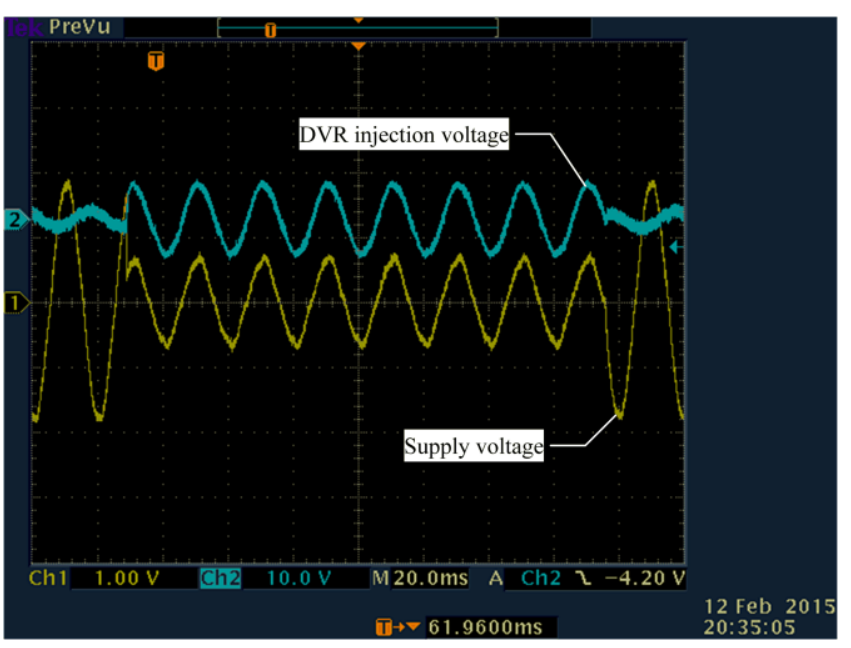

Figure 12. Hybrid System Experimental results: $0.14 \mathrm{~s}$ Three phase sag to $35 \%$ of nominal voltage. Cyan trace: DVR phase-a injection voltage $(100 \mathrm{~V} / \mathrm{div})$. Yellow trace: Phase-a supply voltage (100V/div.). Injection transformer boost ratio: $2: 1$.

TABLE I

SMES PARAMETERS

\begin{tabular}{cr}
\hline \hline Case & Ene1 \\
\hline Hybrid System & 6 \\
SMES- & \\
$(2 \mathrm{~s})$ & \\
SMES- & 38 \\
$(2$ minute $)$ &
\end{tabular}

Without battery storage, the SMES needs to be able to compensate long-term undervoltages. The nominal supply $d q$ axis voltage has no quadrature component, so the direct axis voltage $V_{d \_n o m}$ is the peak voltage in the experimental system, $169.7 \mathrm{~V}$. During a sag with no phase jump, the supply voltage falls to $V_{d_{-} \text {sag }}$ which is $80 \%$ of $V_{d_{-} \text {nom }}$ or $135.8 \mathrm{~V}$. Two cases of sag duration have been considered; a sag lasting two seconds and a sag lasting two minutes. The energy required by the DVR inverter during the two second sag was found to be $638 \mathrm{~J}$ from (20)-(26), whereas the energy required to support the two minute sag was found to be $38251 \mathrm{~J}$ based on IGBT module loss parameters given in [37]. The design procedure described in [38] was then used to estimate the superconducting material requirement assuming a working temperature of $50 \mathrm{~K}$. The coil design for the different cases and overall superconducting material cost based on the price of $2 \mathrm{G}$ HTS (high temperature superconductor) of $\$ 400 / \mathrm{kA}-\mathrm{m}$ [39] is given in Table 1. A complete techno-economic analysis of the benefits of the hybrid system is beyond the scope of this work but the simplified calculation above shows that a significant reduction in superconducting material cost can be achieved by hybridisation with a battery. This would be offset by the additional cost the battery system but worsened by the cost of SMES refrigeration equipment which are not included in the analysis.
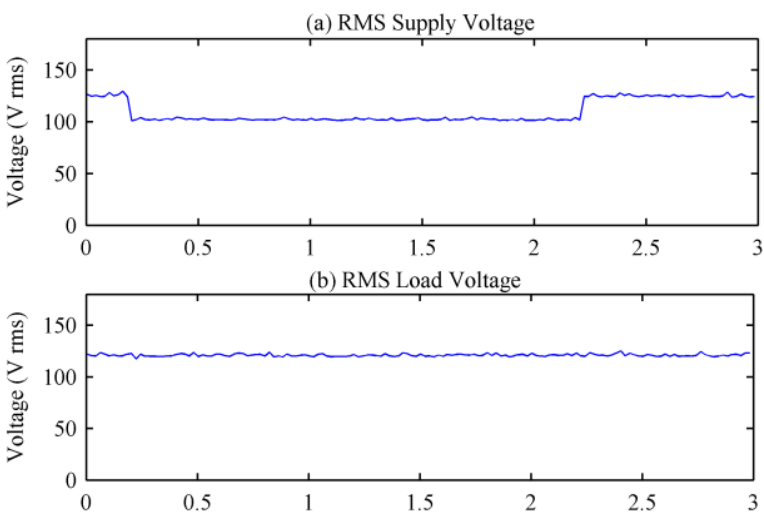

(c) DC Bus Voltage
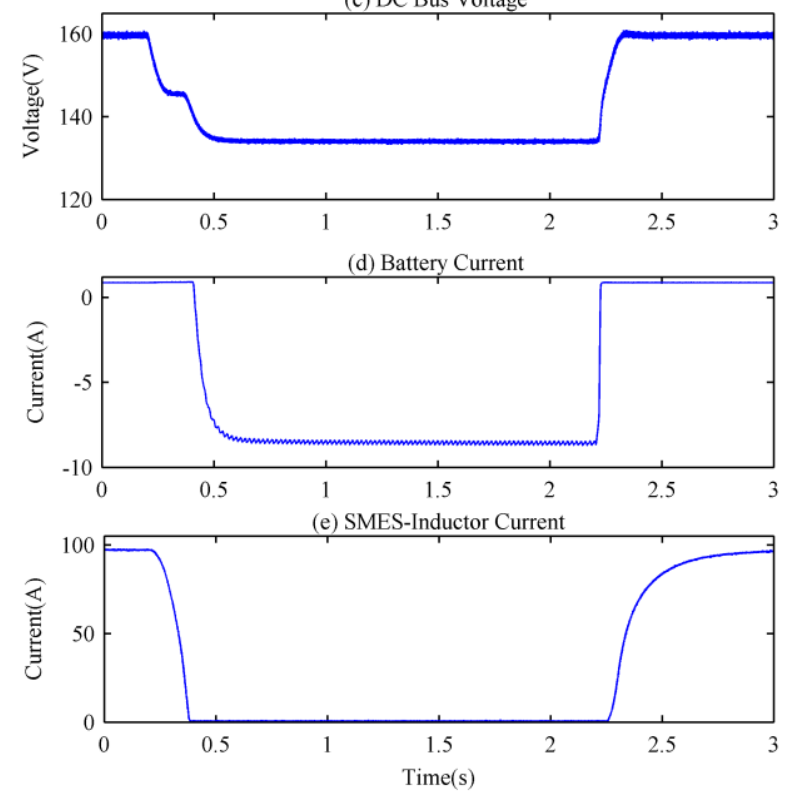

Figure 13. Hybrid System Experimental results: Long-term three phase undervoltage (a) RMS supply phase-voltage. (b) RMS load phasevoltage (c) DC Bus Voltage (d) Battery Current (e) SMES-inductor current.

\section{CONCLUSIONS}

The performance a novel hybrid DVR system topology has been assessed experimentally and shown to effectively provide voltage compensation for short-term sags and long-term under-voltages. A prototype system has been developed which demonstrates an effective method of interfacing SMES and battery energy storage systems to support a three phase load. The system has been shown to autonomously prioritise the use of the short-term energy storage system to support the load during deep, short-term voltage sags and a battery for lower depth, long-term under-voltages. This can have benefits in terms of improved voltage support capability and reduced costs compared with a SMES-based system. Additional benefits include reduced battery power rating requirement and an expected improvement in battery life compared with a battery-only system due to reduced battery power cycling and peak discharge power. 


\section{APPENDIX}

TABLE AI INVERTER SYSTEM PARAMETERS
Switching frequency
Injection transformer rating
Injection transformer boost ratio
IGBT Modules [34]
Filter inductance
DC Bus capacitor
PLL PI gains
Load nominal voltage
Aux. Supply
Sag detect threshold: Vthreshold

TABLE AII

SMES-EMULATOR SYSTEM PARAMETERS

$\begin{array}{ll}\text { Switching frequency } & 500 \mathrm{~Hz} \\ \text { MOSFET (Q1, Q2) 2 in parallel in each leg. } & \text { IXFN140N30P } \\ \text { Diode (D1, D2) 2 in parallel in each leg. } & \text { DSEI2X121-02A } \\ \text { Inductor LSMES } & 15 \mathrm{mH} \\ \text { DC Bus capacitor } & 1.5 \mathrm{mF} \\ \text { Droop gain } & 0.65 \mathrm{~A} / \mathrm{V} \\ \text { CR Snubber } & 3.3 \mathrm{Ohm}+100 \mathrm{nF}\end{array}$

TABLE AIII

BATTERY SYSTEM PARAMETERS

$\begin{array}{ll}\text { Battery voltage } & 48 \mathrm{~V}(4 \times 12 \mathrm{~V}) \\ \text { Battery type } & \text { Sealed lead acid } 75 \mathrm{Ah} \\ \text { IGBT Module } & \text { MG1502YS50 } \\ \text { Power Inductor } & 2 \times 1.8 \mathrm{mH} \text { in parallel } \\ \text { Low side capacitor } & 4700 \mu \mathrm{F} \\ \text { DC Bus capacitor } & 6600 \mu \mathrm{F} \\ \text { Droop gain } & 0.45 \mathrm{~A} / \mathrm{V} \\ \text { Maximum battery charge current } & 800 \mathrm{~mA} \\ \text { Maximum battery discharge current } & 32 \mathrm{~A}\end{array}$

TABLE AIV

EXPERIMENTAL SYSTEM PARAMETERS

\begin{tabular}{ll}
\multicolumn{2}{c}{ EXPERIMENTAL SYSTEM PARAMETERS } \\
\hline Load & $1.4 \mathrm{~kW}$ resistive \\
Line impedance & $5 \Omega$, resistive \\
Step-down transformer ratio & $2: 1$ \\
Three phase sag fault impedance & $3 \Omega$ resistive \\
Single phase under-voltage fault impedance & $25 \Omega$ resistive \\
ADC card & NI USB-6463 \\
Sample rate & $10 \mathrm{kHz}$
\end{tabular}

\section{ACKNOWLEDGMENT}

The author would like to thank financial support from EPSRC EP/K01496X/1 and support from the Royal Academy of Engineering's Research Fellowship programme.

\section{REFERENCES}

[1] P.K. Ray, S.R. Mohanty, N. Kishor, and J.P.S. Catalao, "Optimal Feature and Decision Tree-Based Classification of Power Quality Disturbances in Distributed Generation Systems," Sustainable Energy, IEEE Trans., vol. 5, Sept. 2014, pp. 200-208.

[2] D. Novosel, G. Bartok, G. Henneberg, P. Mysore, D. Tziouvaras, and S. Ward, "IEEE PSRC Report on Performance of Relaying During Wide-Area Stressed Conditions," Power Delivery, IEEE Trans., vol. 25, Jan. 2010, pp. 3-16.

[3] "IEEE Recommended Practice for Monitoring Electric Power Quality," in IEEE Std 1159-1995, ed. New York, NY: IEEE Standards Board, 1995, p. i.

[4] S. Jothibasu and M.K. Mishra, "A Control Scheme for Storageless DVR Based on Characterization of Voltage Sags," Power Delivery, IEEE Trans., vol. 29, July 2014, pp. 2261-2269.
B. Otomega and T. Van Cutsem, "Undervoltage Load Shedding Using Distributed Controllers," Power Systems, IEEE Trans., vol. 22, Nov. 2007, pp. 1898-1907.

L. Chun, J. Savulak, and R. Reinmuller, "Unintentional Islanding of Distributed Generation: Operating Experiences From Naturally Occurred Events," Power Delivery, IEEE Trans., vol. 29, Jan. 2014, pp. 269-274.

S. Tohidi, H. Oraee, M.R. Zolghadri, S. Shiyi, and P. Tavner, "Analysis and Enhancement of Low-Voltage Ride-Through Capability of Brushless Doubly Fed Induction Generator," Industrial Electronics, IEEE Trans., vol. 60, March 2013, pp. 1146-1155.

R. Lawrence, "Voltage optimization," Industry Apps. Mag., IEEE, vol. 12, Sept. 2006, pp. 28-33.

P. Kanjiya, B. Singh, A. Chandra, and K. Al-Haddad, "'SRF Theory Revisited" to Control Self-Supported Dynamic Voltage Restorer (DVR) for Unbalanced and Nonlinear Loads," Industry Applications, IEEE Trans., vol. 49, May 2013, pp. 2330-2340.

A.M. Rauf and V. Khadkikar, "An Enhanced Voltage Sag Compensation Scheme for Dynamic Voltage Restorer," Industrial Electronics, IEEE Trans., vol. 62, Oct. 2015, pp. 2683-2692.

V.K. Ramachandaramurthy, C. Fitzer, A. Arulampalam, C. Zhan, M. Barnes, and N. Jenkins, "Control of a battery supported dynamic voltage restorer," Generation, Transmission and Distribution, IEE Proceedings., vol. 149, Sept. 2002, pp. 533-542. J.G. Nielsen and F. Blaabjerg, "A detailed comparison of system topologies for dynamic voltage restorers," Industry Applications, IEEE Trans., vol. 41, Sept. 2005, pp. 1272-1280.

[13] D. Somayajula and M.L. Crow, "An Integrated Dynamic Voltage Restorer-Ultracapacitor Design for Improving Power Quality of the Distribution Grid," Sustainable Energy, IEEE Trans., vol. 6, April 2015, pp. 616-624.

[14] W. Bingsen and G. Venkataramanan, "Dynamic Voltage Restorer Utilizing a Matrix Converter and Flywheel Energy Storage," Industry Applications, IEEE Trans., vol. 45, Jan. 2009, pp. 222231.

H.J. Kim, K.C. Seong, J.W. Cho, J.H. Bae, K.D. Sim, S. Kim, E.Y. Lee, K. Ryu, and S.H. Kim, "3 MJ/750 kVA SMES System for Improving Power Quality," Applied Superconductivity, IEEE Trans., vol. 16, June 2006, pp. 574-577.

[16] S. Jing, T. Yuejin, Y. Kai, C. Lei, R. Li, L. Jingdong, and C. Shijie, "SMES Based Dynamic Voltage Restorer for Voltage Fluctuations Compensation," Applied Superconductivity, IEEE Trans., vol. 20, May 2010, pp. 1360-1364.

[17] H.M.S.C. Herath, V.J. Gosbell, and S. Perera, "Power quality (PQ) survey reporting: discrete disturbance limits," Power Delivery, IEEE Trans., vol. 20, Sept. 2005, pp. 851-858.

[18] S. Jae Woong, C. Youngho, K. Seog-Joo, M. Sang Won, and H. Kyeon, "Synergistic Control of SMES and Battery Energy Storage for Enabling Dispatchability of Renewable Energy Sources," Applied Superconductivity, IEEE Trans., vol. 23, June 2013, pp. 5701205-5701205.

[19] J. Li, M. Zhang, Q. Yang, Z. Zhang, and W. Yuan, "SMES/Battery Hybrid Energy Storage System for Electric Buses," IEEE Transactions on Applied Superconductivity, vol. 26, Feb. 2016, pp. $1-5$.

J. Deng, J. Shi, Y. Liu, and Y. Tang, "Application of a hybrid energy storage system in the fast charging station of electric vehicles," IET Generation, Transmission \& Distribution, vol. 10, March 2016, pp. 1092-1097.

[21] N. Zanxiang, X. Xi, K. Qing, R. Aggarwal, Z. Huiming, and Y. Weijia, "SMES-Battery Energy Storage System for Conditioning Outputs From Direct Drive Linear Wave Energy Converters," Applied Superconductivity, IEEE Trans., vol. 23, June 2013, pp. 5000705-5000705.

[22] P. Jayaprakash, B. Singh, D.P. Kothari, A. Chandra, and K. AlHaddad, "Control of Reduced-Rating Dynamic Voltage Restorer With a Battery Energy Storage System," Industry Applications, IEEE Trans., vol. 50, Jul. 2014, pp. 1295-1303.

[23] J.G. Nielsen, F. Blaabjerg, and N. Mohan, "Control strategies for dynamic voltage restorer compensating voltage sags with phase jump," in Applied Power Electronics Conference and Exposition, 2001. Sixteenth Annual IEEE, pp. 1267-1273 vol.2.

J.G. Nielsen, M. Newman, H. Nielsen, and F. Blaabjerg, "Control and testing of a dynamic voltage restorer (DVR) at medium 
voltage level," Power Electronics, IEEE Trans., vol. 19, May 2004, pp. 806-813.

[25] C. Fitzer, M. Barnes, and P. Green, "Voltage sag detection technique for a dynamic voltage restorer," Industry Applications, IEEE Trans., vol. 40, Feb. 2004, pp. 203-212.

[26] C. Gavriluta, J.I. Candela, C. Citro, J. Rocabert, A. Luna, and P. Rodriguez, "Decentralized Primary Control of MTDC Networks With Energy Storage and Distributed Generation," Industry Applications, IEEE Trans., vol. 50, April 2014, pp. 4122-4131.

[27] J. Schonberger, R. Duke, and S.D. Round, "DC-Bus Signaling: A Distributed Control Strategy for a Hybrid Renewable Nanogrid," Industrial Electronics, IEEE Transactions on, vol. 53, Oct. 2006, pp. $1453-1460$.

[28] S. Chattopadhyay and S. Das, "A Digital Current-Mode Control Technique for DC-DC Converters," Power Electronics, IEEE Trans., vol. 21, Nov. 2006, pp. 1718-1726.

[29] M. Castilla, J.M. Guerrero, J. Matas, J. Miret, and J. Sosa, "Comparative study of hysteretic controllers for single-phase voltage regulators," IET Power Electron., vol. 1, Mar. 2008, pp. 132-143.

[30] R. Venkataramanan, A. Sabanovic, and S. Cuk, "Sliding mode control of DC-to-DC converters," in IEEE Conference On Industrial Electronics, San Francisco, CA, USA, 1985, pp. 251258.

[31] J. Horak, "Power Quality: Measurements of Sags and Interruptions," in IEEE/PES Transmission and Distribution Conference and Exhibition, 2005/2006, Dallas, TX, pp. 733-739.

[32] M.H. Bierhoff and F.W. Fuchs, "Semiconductor losses in voltage source and current source IGBT converters based on analytical derivation," in Power Electronics Specialists Conference, 2004 IEEE 35th Annual, Aachen, Germany, pp. 2836-2842 Vol.4.

[33] F. Casanellas, "Losses in PWM inverters using IGBTs," Electric Power Applications, IEE Proceedings, vol. 141, Sep 1994, pp. 235-239.

[34] 2MBI150U2A-060-50 Datasheet. Fuji Electric Ltd., Edison, NJ, Available:

http://www.americas.fujielectric.com/sites/default/files/2MBI150U 2A-060.pdf

[35] J.H. Yan, W.S. Li, and Q.Y. Zhan, "Failure mechanism of valveregulated lead-acid batteries under high-power cycling," J. Power Sources, vol. 133, May 2004, pp. 135-140.

[36] X.Y. Chen, J.X. Jin, Y. Xin, S. Bin, C.L. Tang, Y.P. Zhu, and R.M. Sun, "Integrated SMES Technology for Modern Power System and Future Smart Grid," Applied Superconductivity, IEEE Trans., vol. 24, Oct. 2014, pp. 1-5.

[37] FF600R06ME3 Datasheet. Infineon Technologies AG, Neubiberg, Germany, Available: http://www.infineon.com/dgd1/Infineon-FF600R06ME3-DSv03 01-en de.pdf?fileId=db3a304318a6cd680118e5130f161311

[38] W. Yuan, W. Xian, M. Ainslie, Z. Hong, Y. Yan, R. Pei, Y. Jiang, and T.A. Coombs, "Design and Test of a Superconducting Magnetic Energy Storage (SMES) Coil," Applied Superconductivity, IEEE Trans., vol. 20, May 2010, pp. 13791382 .

[39] V. Selvamanickam and J. Dackow, "Progress in SuperPower's 2G HTS Wire Development and Manufacturing," in DOE Advanced Cables \& Conductors Peer Review, , Alexandria, VA, 2010.

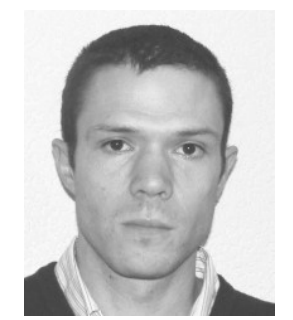

Anthony Gee received his BSc degree in Cybernetics and Control Engineering from the University of Reading, England. He then completed a $\mathrm{PhD}$ in supercapacitor/battery hybrid energy storage systems at the University of Bath. Since then he has worked with Williams Advanced Engineering and is currently working at the Energy Management Group, University of Bristol as a power electronics hardware design engineer. His research interests are in power electronic converters, motor drives and renewable energy systems.

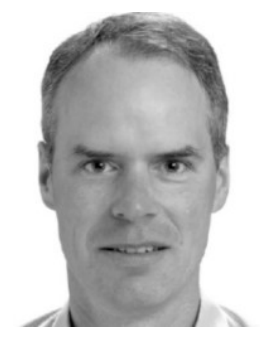

Francis Robinson (M'1988) gained a $\mathrm{PhD}$ from Heriot-Watt University, Edinburgh, Scotland. He has been a lecturer at the Department of Electronic and Electrical Engineering, University of Bath since 1990 , and is a member of the Electromagnetic, Machines and Drives Group. His teaching and research are primarily related to power electronics and drives. He has previously worked as a power electronics design engineer with Posidata (Dana) LTD, Rutherford Appleton Laboratory, and GEC Small Machines Ltd. Dr Robinson is a chartered engineer in the UK and a member of the IET and IEEE.

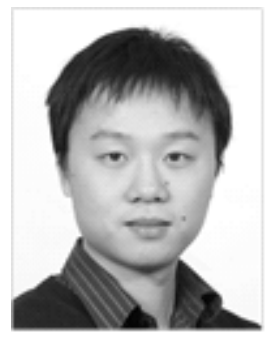

Weijia Yuan received his Bachelor degree from Tsinghua University and his $\mathrm{PhD}$ from the University of Cambridge. He then became both a research associate in the Engineering Department and a junior research fellow at Wolfson College, both at the University of Cambridge. Dr Yuan joined the University of Bath as a lecturer (US equivalent: Assistant Professor) in 2011. Dr Yuan's research interests focus on electrical power applications of superconductivity including fault current limiters, machines and power transmission lines. He has extensive research experience in modelling of superconducting devices and building superconducting magnets. 